\title{
Predictors of substantial improvement in physical function six months after lumbar surgery: is early post-operative walking important? A prospective cohort study
}

\author{
Sarah J. Gilmore ${ }^{1,2^{*}}$ D, Andrew J. Hahne ${ }^{2}$, Megan Davidson ${ }^{2}$ and Jodie A. McClelland ${ }^{2}$
}

\begin{abstract}
Background: Resuming walking after lumbar surgery is a common focus of early post-operative rehabilitation, however there is no knowledge about whether increased walking is associated with better functional outcomes. This study aimed to determine whether time spent walking in the week after lumbar surgery, along with co-morbidities, pre-operative pain duration, pre-operative physical activity or function, or surgical variables predict substantial improvement in physical function six months after lumbar surgery.

Methods: A prospective cohort study design was utilized. Participants undergoing lumbar surgery (discectomy, decompression, fusion) were recruited between April and November 2016. Predictor variables were collected pre-operatively (age, sex, smoking status, obesity, diabetes, depression, anxiety, pre-operative pain duration, neurological deficit, physical activity levels, mobility restriction, function) and early post-operatively (post-operative walking time, surgical procedure, single/multi-level surgery). Outcome variables (physical function, back pain and leg pain severity) were measured pre-operatively and six-months post-operatively. Logistic regression analysis was used to establish prediction of substantial improvement in outcome at six months.
\end{abstract}

Results: Participants ( $N=233 ; 50 \%$ female; age 61 ( $S D=14$ ) years) who walked more in the first post-operative week were more likely to have substantially improved function on the Oswestry Disability Questionnaire at six months (OR $1.18,95 \% \mathrm{Cl} 1.02-1.37)$, as were participants with $<12$ months pre-operative pain (OR 2.71, 95\%Cl 1.28-5.74), and those with lower pre-operative function (OR 4.02,95\%Cl 2.33-6.93). Age < 65 years (OR 2.36, 95\%Cl 1.14-4.85), and $<12$ months pre-operative pain (OR 3.52 95\%Cl 1.69-7.33) predicted substantial improvement on the SF-36 Physical Component Summary. There were no significant predictors for substantial improvement in either leg or back pain.

Conclusions: Walking time in the week after lumbar surgery is one of several predictors of substantial improvement in function at six months. Further research is required to determine whether intervention designed to increase walking early after lumbar surgery results in improved longer-term recovery of function.

Trial registration: Australian New Zealand Clinical Trials Registry (ANZCTR), registration number 12616000747426. Retrospectively registered on the 7th of June 2016.

Keywords: Physical therapy, Physical activity, Lumbar surgery, Lumbar fusion, Discectomy, Laminectomy

\footnotetext{
* Correspondence: sarah.gilmore@svha.org.au

'St Vincent's Private Hospital Melbourne, 59 Victoria Parade, Fitzroy, VIC 3065,

Australia

${ }^{2}$ La Trobe University, Plenty Rd, Bundoora, Melbourne, VIC 3086, Australia
}

(c) The Author(s). 2019 Open Access This article is distributed under the terms of the Creative Commons Attribution 4.0 International License (http://creativecommons.org/licenses/by/4.0/), which permits unrestricted use, distribution, and reproduction in any medium, provided you give appropriate credit to the original author(s) and the source, provide a link to the Creative Commons license, and indicate if changes were made. The Creative Commons Public Domain Dedication waiver (http://creativecommons.org/publicdomain/zero/1.0/) applies to the data made available in this article, unless otherwise stated. 


\section{Background}

The number of surgical procedures performed for the management of lumbar spinal conditions has increased considerably over the previous two decades [1-3]. While surgical techniques have advanced over this time, whether surgical intervention leads to improved patient outcome remains inconclusive [4-6], with up to $40 \%$ of patients reporting no improvement in symptoms following surgery [7]. It may be possible to improve the success of surgical intervention through rehabilitation programs specifically designed to optimise post-operative recovery. However, there has been very little research investigating the effectiveness of rehabilitation after lumbar spine surgery $[8,9]$.

The majority of patients undergoing lumbar surgery in Australia and the UK are seen by a physiotherapist during their hospital admission. While the focus of early rehabilitation is commonly on resuming walking [10-12], walking time in the post-operative period has not previously been evaluated for its association with longer term outcomes in people undergoing lumbar surgery. A number of other factors have been shown to predict outcomes following lumbar surgery including age [13, 14], sex [13, 15], smoking status [16] obesity [13], diabetes [17], depression [18], anxiety [13], symptom duration [15], and pre-operative disability $[13,14,16]$. To further the current understanding about recovery after lumbar surgery is important that additional potential predictive factors, such as walking time in the immediate post-operative period, are evaluated relative to these existing predictors of surgical outcome.

Objective measurement using accelerometry is a valid [19] and increasingly common method of quantifying walking and physical activity after lumbar surgery. Recent research indicates that patients do very little walking in the first post-operative week [20], a trend that continues for up to two years after surgery [21]. It also appears that patients perform significantly less walking six months after lumbar surgery than they have the capacity to do [22], suggesting that it may be possible to increase walking time through targeted intervention. This discrepancy further supports for the need to investigate whether increased walking time is associated with better post-operative outcomes.

The aim of this study, as described in the published protocol [23], was to investigate which variables predict improvement of a) physical function and b) back and leg pain severity six months after lumbar spinal surgery, with a focus on walking time early after surgery.

\section{Methods}

\section{Study design}

A prospective cohort study design was used. Ethics approval was obtained from the St Vincent's Hospital
Melbourne Human Research Ethics Committee (Reference: LRR 098/15).

\section{Participants}

Participants were recruited from St Vincent's Private Hospital Melbourne (SVPHM). Patients aged 18 years or older, admitted for surgical management of a disc prolapse, degenerative disc disease, lumbar spinal stenosis and/or degenerative spondylolysthesis were invited to participate. Patients were excluded if surgery was for the management of fractures or tumours, if they were unable to provide informed consent, or if they had a co-existing neurological or musculoskeletal condition resulting in impaired physical function. There were no exclusion criteria based on the duration or nature of pre-operative symptoms.

\section{Procedure}

Potential participants were identified from the neurosurgical theatre lists of the 11 neurosurgeons performing spinal surgery at SVPHM at the time of this study. Prior to surgery, the research physiotherapist informed eligible participants about the study aims and procedures, and provided them with an information pack and pre-operative outcome measures. Written informed consent was obtained from all individual participants included in the study.

Post-operatively, participants wore an ActivPAL3 accelerometer (PAL Technologies, Glasgow, UK) to record total walking time over the first seven post-operative days, commencing at 8 am on the morning after surgery. On discharge from hospital, participants were provided with instructions to return the monitor after the recording period was completed. Six months after surgery participants were posted follow-up outcome measures to complete, which were returned to the researchers by mail.

All participants received routine post-operative physiotherapy treatment that commenced the day after surgery. This consisted of an exercise program (trunk and lower limb strengthening and stretching exercises, individualised based on patient presentation), a bed mobility and gait assessment, and a walking program. There were no post-operative restrictions on walking, all participants were encouraged to complete regular walks over a comfortable distance, increasing the duration and frequency of walking as tolerated. All participants were advised to avoid bending, lifting, or twisting for six weeks after surgery. Five of the eleven neurosurgeons advised patients to sit for no longer then $15 \mathrm{~min}$ at a time for six weeks, the remaining six had no postoperative sitting restrictions. 


\section{Predictor variables}

Total walking time was measured over the first post-operative week, using the ActivPAL3 accelerometer. The ActivPAL3 has been shown to be a valid measurement tool early after lumbar spine surgery (19). In addition to post-operative walking time, an additional 14 predictor variables were included, based on previous evidence to suggest a correlation with outcome after lumbar surgery, or a strong theoretical rational for their inclusion. These variables were age, sex, current smoking status, obesity, diabetes, depression, anxiety, pre-operative pain duration, presence of a pre-operative neurological deficit, pre-operative activity level, mobility, and function, the surgical procedure performed and the number of operated vertebral levels (Table 1).

Depression was assessed using the Patient Health Questionnaire Depression Scale (PHQ-9), a valid and reliable measure of depression, that has been recommended for use in the chronic back pain population [24, 25]. Anxiety was assessed using the Generalised Anxiety Disorder 7-item Scale (GAD-7), a validated measure used to screen for, and assess the severity of anxiety [26]. Neurological deficit was assessed by participant self-report of any changes to the sensation or strength in their affected lower limb. This level of information was deemed appropriate, as any sensory or motor deficit that the participant was not aware of was unlikely to impact physical function. Pre-operative activity was assessed using the International Physical Activity Questionnaire Short Form (IPAQ-SF), a self-report questionnaire assessing physical activity over the previous seven-day period $[27,28]$. Pre-operative function was assessed using the pre-operative Oswestry Disability Questionnaire (ODQ) score. Pre-operative mobility was categorised into limited or not limited, based on the response to Section 4 (Walking) on the ODQ. A score of three or more indicated limited mobility - unable to walk more than $500 \mathrm{~m}$, requiring a walking aid, or confined to bed.

\section{Outcome variables}

The outcome variables were described in terms of change between the pre-operative assessment, and six months after surgery. The primary outcome variable was

Table 1 Outcome and predictor variables

\begin{tabular}{|c|c|c|c|c|}
\hline & Outcome measurement tool & \multicolumn{3}{|c|}{ Logistic multivariable analysis categories } \\
\hline \multicolumn{5}{|l|}{ Outcome variables (Pre-operative/6 months) } \\
\hline \multirow[t]{2}{*}{ Physical function } & Oswestry Disability Questionnaire (ODQ) (0-100) & 1. $\angle S C B(18.8)$ & 2. $\geq$ SCB (18.8) & \\
\hline & $\begin{array}{l}\text { SF-36 Physical Component Summary } \\
\text { (SF-36 PCS) (0-100) }\end{array}$ & 1. $<$ SCB $(-6.2)$ & 2. $\geq \operatorname{SCB}(-6.2)$ & \\
\hline Back Pain & Numerical pain rating scale (NRPS) (0-10) & 1. $<\mathrm{SCB}(2.5)$ & 2. $\geq S C B(2.5)$ & \\
\hline Leg Pain & Numerical pain rating scale (NRPS) (0-10) & 1. $<\mathrm{SCB}(2.5)$ & 2. $\geq \operatorname{SCB}(2.5)$ & \\
\hline \multicolumn{5}{|l|}{ Predictor variables } \\
\hline Total walking time (1st 7 post-op days) & ActivPAL3 accelerometer & \multicolumn{3}{|l|}{ Hours (continuous) } \\
\hline Age & - & 1. $<65$ years & \multicolumn{2}{|l|}{ 2. $\geq 65$ years } \\
\hline Sex & - & 1. Male & \multicolumn{2}{|l|}{ 2. Female } \\
\hline Current smoking status & - & 1. Non-smoker & \multicolumn{2}{|l|}{ 2. Smoker } \\
\hline Obesity & Body Mass Index (BMI) & 1. $\mathrm{BMI}<30$ & \multicolumn{2}{|l|}{ 2. $\mathrm{BMI} \geq 30$} \\
\hline Diabetes & - & 1. Not diabetic & \multicolumn{2}{|l|}{ 2. Diabetic } \\
\hline Depression & $\begin{array}{l}\text { Patient Health Questionnaire Depression } \\
\text { Scale (PHQ-9) }\end{array}$ & $\begin{array}{l}\text { 1. No depression: } \\
\mathrm{PHQ}-9<10\end{array}$ & \multicolumn{2}{|l|}{$\begin{array}{l}\text { 2. Increased likelihood of } \\
\text { depression: } \mathrm{PHQ}-9 \geq 10\end{array}$} \\
\hline Anxiety & $\begin{array}{l}\text { Generalised Anxiety Disorder } 7 \text { Item } \\
\text { Scale (GAD-7) }\end{array}$ & $\begin{array}{l}\text { 1. No anxiety: } \\
\text { PHQ-9 }<10\end{array}$ & \multicolumn{2}{|l|}{$\begin{array}{l}\text { 2. Increased likelihood of } \\
\text { anxiety: } \mathrm{PHQ}-9 \geq 10\end{array}$} \\
\hline Pre-operative pain duration & - & 1. $<12$ months & \multicolumn{2}{|l|}{ 2. $\geq 12$ months } \\
\hline Neurological deficit & Self-report & 1. No deficit & \multicolumn{2}{|l|}{ 2. Sensory/motor deficit } \\
\hline Pre-operative activity & $\begin{array}{l}\text { International Physical Activity Questionnaire } \\
\text { Short Form (IPAQ-SF) }\end{array}$ & $\begin{array}{l}\text { 1. Moderate/high } \\
\text { activity }\end{array}$ & \multicolumn{2}{|l|}{ 2. Low activity } \\
\hline Pre-operative mobility & $\begin{array}{l}\text { ODQ, Section } 4 \text { (restricted mobility: score } \geq 3 \text { : } \\
\text { unable to walk more than } 500 \text { m, } \\
\text { or requires a stick, crutches or other support) }\end{array}$ & $\begin{array}{l}\text { 1. Unrestricted } \\
\text { mobility }\end{array}$ & \multicolumn{2}{|l|}{ 2. Restricted mobility } \\
\hline Pre-operative function & ODQ classification (\%) & 1. $0-20 \% \quad$ 2. $21-40 \%$ & 3. $41-60 \% \quad 4.61-80 \%$ & 5. $81-100 \%$ \\
\hline Surgical procedure & - & 1. Decompression & 2. Discectomy & 3. Fusion \\
\hline Number of vertebral levels & - & 1. Single level & \multicolumn{2}{|l|}{ 2. Multi-level } \\
\hline
\end{tabular}


self-reported physical function, measured using the Oswestry Disability Questionnaire (ODQ) [29] and the Short Form 36 Physical Component Summary (SF-36 PCS) (Version 2) [30]. The secondary outcome variables were back and leg pain intensity, measured using the Numeric Pain Rating Scale (NPRS) (0-10) where a higher score indicates more intense pain. The ODQ, SF36 and the NPRS are commonly used to evaluate outcome following spinal surgery, and have all been validated in back pain populations [31].

At six months participants were also asked to report on their overall satisfaction with their post-operative recovery (Likert scale, 1-5), and if they required any ongoing medical intervention directly related to their surgical procedure.

\section{Data analysis}

Data from the ActivPAL3 were downloaded using PAL Technologies software, and analysed to identify the cumulative amount of time spent walking over the sevenday monitoring period. Descriptive analysis of the data and testing for normality were performed. The four outcome variables (ODQ, SF-36 (PCS), back pain, leg pain) were dichotomised based on the change-score thresholds required to achieve a minimum clinically important difference (MCID) $[32,33]$ and substantial clinical benefit (SCB) [33] (Table 2). The MCID identifies the change required on a given outcome measure to demonstrate a clinically meaningful improvement in symptoms, and is widely used in lumbar pathology research [32]. The SCB threshold however, identifies the change in outcome required to demonstrate substantial improvement in symptoms [33]. Analysis of outcome based on the MCID and SCB allows for the change in scores to be categorised as no improvement $(<\mathrm{MCID})$, minimal improvement ( $>\mathrm{MCID},<\mathrm{SCB})$ and substantial improvement $(>\mathrm{SCB})$. The change in physical function, back pain and leg pain over the six months were analysed using paired $t$-tests, and by using descriptive statistics to examine the proportion of participants who achieved the MCID and SCB thresholds.

Table 2 MCID and SCB thresholds

\begin{tabular}{lll}
\hline Outcome & MCID (points change) & SCB (points change) \\
\hline ODQ & 10 & 18.8 \\
SF-36 (PCS) & 4.9 & 6.2 \\
NPRS (back pain) & 2 & 2.5 \\
NRPS (leg pain) & 1.6 & 2.5 \\
\hline
\end{tabular}

MCID Minimal Clinically Important Difference, SCB Substantial Clinical Benefit, ODQ Oswestry Disability Questionnaire, SF-36 Short Form 36 Physical

Component Summary, NRPS Numerical Pain Rating Scale

\section{Univariate analysis of predictors of outcome}

Pearson's Correlations were performed to calculate the association between the 15 predictor variables and achievement of the SCB threshold for each of the four outcome measures (ODQ; $\geq 18.8$; SF-36 (PCS): 26.2; NPRS: $\geq 2.5$ ) [33].

\section{Multivariable logistic regression analysis}

The predictor variables that were associated with achieving the SCB threshold at a significance level of $p<0.1$ in the univariate analysis were entered into a multivariate logistic regression model, using a Backward Wald stepwise method. The threshold of $p<0.1$ at the univariate stage was chosen to minimise the chance of eliminating potentially predictive variables at this stage [34]. Primary data analysis was conducted using logistic regression analysis and participants with a full data set (no missing outcome or predictor variables).

\section{Sensitivity analysis}

A secondary sensitivity analysis of the prediction models was performed by a) completing linear regression analysis of the predictor variables that were associated with change in outcome $(p<0.1)$, where change scores were continuous and not dichotomised, and $b$ ) using multiple imputation to estimate missing values in both the logistic and linear regression analyses. Comparative analysis of the pre-operative and demographic data of participants excluded due to missing data was performed using $t$-tests.

All analyses were completed in SPSS version 24 (IBM, New York, USA). The target sample size for this study was calculated based on the recommendation of five to ten outcome events per predictor variable (EPV) [35]. It was estimated that SCB would be achieved by $50 \%$ of participants on the 15 predictor variables, therefore, the minimum recommended number of participants needed to complete these analyses was 150 . It was expected that a total of approximately 300 patients would be admitted for lumbar spinal surgery over the six-month recruitment period. To allow for participant exclusion, variation in EVP, missing data and loss to follow-up, the minimum recruitment target was 250 participants.

\section{Results}

\section{Participant characteristics}

A total of 233 participants consented to participate between April and November 2016. Participant characteristics are presented in Table 3 , and a summary of missing data and reasons for exclusion is presented in Table 4. A further 62 participants were lost to follow-up due to incomplete activity monitor data and loss to follow-up, the remaining 171 participants (73.4\%) were included in the final analysis. There was no statistically 
significant difference in demographic or pre-operative data between participants excluded due to incomplete activity monitor data and loss to follow-up, and those included in the final analysis (Additional file 1: Table S1, S2 in Appendix).

Preliminary analysis of the accelerometer data revealed that a high proportion of participants had removed the activity monitor during the final $24 \mathrm{~h}$ of monitoring. To remove the chance of systematic error as a result of incomplete data, the seventh day of monitoring has been removed from analysis. The total walking time represents the first six post-operative days.

There was a statistically significant improvement in physical function (ODQ and SF-36 PCS), back pain, and leg pain from baseline to six months after surgery (Table 5). Descriptive statistical analysis identified that the proportion of participants who achieved over and above the MCID threshold was between 64\% (back pain) and $72 \%$ (SF-36 PCS). Between 51\% (ODQ) and 66\% (SF-36 PCS) of participants exceeded the threshold required to demonstrate a substantial clinical benefit. The average score for overall satisfaction with post-operative recovery was 4.11 (Likert scale, $1-5$ ), with $41 \%$ of participants reporting a satisfaction score of 5 (definitely satisfied). Seventeen participants (7\%) reported post-operative complications that required ongoing medical intervention (revision/further surgery $N=10$; infection $N=3$; deep vein thrombosis $\mathrm{N}=1$; cerebrospinal fluid leak $\mathrm{N}=1$; hematoma $\mathrm{N}=1$; reason not provided $\mathrm{N}=1$ ). There was no significant association between the time spent walking and post-operative complications.

\section{Univariate analysis}

Greater post-operative total walking time was correlated with achieving the SCB threshold on both the ODQ $(p=0.05)$ and the SF-36 (PCS) $(p=0.01)$ (Additional file 1: Table S3 in Appendix). In addition, female sex, pre-operative pain duration of less than 12 months, low pre-operative activity, restricted pre-operative mobility, lower pre-operative function and single-level surgery were correlated with achieving the SCB threshold on the SF-36 (PCS) $(p<0.1)$; An age of less than 65 years, no pre-operative anxiety (indicated by a negative correlation between anxiety and change in outcome, Additional file 1: Table S1 in Appendix) and a pre-operative pain duration of less than 12 months were correlated with achieving the SCB threshold on the SF-36 (PCS) $(p<0.1)$. Female sex, lower pre-operative function and single-level surgery were correlated with achieving the SCB threshold in leg pain scores $(p<0.1)$. Achieving the SCB threshold on the back pain scores was not correlated with any of the predictor variables on univariate analysis.
Table 3 Participant characteristics $(\mathrm{N}=233)$

\begin{tabular}{|c|c|c|}
\hline & $\mathrm{N}$ & (\%) \\
\hline \multicolumn{3}{|l|}{ Age } \\
\hline$<65$ & 119 & $(51 \%)$ \\
\hline$\geq 65$ & 114 & $(49 \%)$ \\
\hline \multicolumn{3}{|l|}{ Sex } \\
\hline Male & 118 & $(51 \%)$ \\
\hline Female & 115 & $(49 \%)$ \\
\hline \multicolumn{3}{|l|}{ Smoking Status } \\
\hline Non-smoker & 214 & $(92 \%)$ \\
\hline Smoker & 18 & $(8 \%)$ \\
\hline Incomplete data & 1 & $(0.4 \%)$ \\
\hline \multicolumn{3}{|l|}{ Obesity } \\
\hline $\mathrm{BMI}<30$ & 154 & $(66 \%)$ \\
\hline $\mathrm{BMI} \geq 30$ & 73 & (31\%) \\
\hline Incomplete data & 6 & $(3 \%)$ \\
\hline \multicolumn{3}{|l|}{ Diabetic } \\
\hline No & 207 & (89\%) \\
\hline Yes & 25 & $(11 \%)$ \\
\hline Incomplete data & 1 & $(0.4 \%)$ \\
\hline \multicolumn{3}{|l|}{ Depression } \\
\hline No $(\mathrm{PHQ}-9<10)$ & 130 & $(56 \%)$ \\
\hline Yes (PHQ-9 $\geq 10)$ & 98 & $(42 \%)$ \\
\hline Incomplete data & 5 & $(2 \%)$ \\
\hline \multicolumn{3}{|l|}{ Anxiety } \\
\hline No $(G A D-7<10)$ & 159 & $(68 \%)$ \\
\hline Yes (GAD-7 $\geq 10)$ & 69 & $(30 \%)$ \\
\hline Incomplete data & 5 & $(2 \%)$ \\
\hline \multicolumn{3}{|c|}{ Pre-operative pain duration } \\
\hline$<12$ months & 106 & $(45 \%)$ \\
\hline$\geq 12$ months & 115 & $(49 \%)$ \\
\hline Incomplete data & 12 & $(5 \%)$ \\
\hline \multicolumn{3}{|c|}{ Neurological deficit (self-report) } \\
\hline No & 17 & $(7 \%)$ \\
\hline Yes & 214 & $(92 \%)$ \\
\hline Incomplete data & 2 & $(1 \%)$ \\
\hline \multicolumn{3}{|c|}{ Pre-operative activity (IPAQ-SF) } \\
\hline Low & 130 & $(56 \%)$ \\
\hline Moderate & 64 & $(27 \%)$ \\
\hline High & 29 & $(12 \%)$ \\
\hline Incomplete data & 10 & $(4 \%)$ \\
\hline \multicolumn{3}{|c|}{ Pre-operative mobility (ODQ Section 4) } \\
\hline Un-restricted $(<3)$ & 113 & $(48 \%)$ \\
\hline Restricted $(\geq 3)^{a}$ & 120 & $(52 \%)$ \\
\hline \multicolumn{3}{|c|}{ Pre-operative function (ODQ category) } \\
\hline $0-20 \%$ & 15 & $(6 \%)$ \\
\hline
\end{tabular}


Table 3 Participant characteristics $(\mathrm{N}=233)$ (Continued)

\begin{tabular}{lll}
\hline & $\mathrm{N}$ & $(\%)$ \\
\hline $21-40 \%$ & 93 & $(40 \%)$ \\
$41-60 \%$ & 85 & $(36 \%)$ \\
$61-80 \%$ & 37 & $(16 \%)$ \\
$81-100 \%$ & 2 & $(1 \%)$ \\
Incomplete data & 1 & $(0.4 \%)$ \\
Surgical procedure & & \\
Decompression & 63 & $(27 \%)$ \\
Discectomy & 96 & $(41 \%)$ \\
Fusion & 74 & $(32 \%)$ \\
Number of vertebral levels & & \\
Single & 175 & $(75 \%)$ \\
Multiple & 58 & $(25 \%)$ \\
\hline
\end{tabular}

BMI Body mass index, PHQ-9 Patient Health Questionnaire 9; GAD-7, Generalised Anxiety Disorder 7-item scale; IPAQ-SF, International Physical Activity Questionnaire Short Form; $\mathrm{ODQ}$, Oswestry Disability Questionnaire; ${ }^{a}$ Restricted mobility: ODQ Section 4 , score of $\geq 3$ (unable to walk more than $500 \mathrm{~m}$, or requires a stick, crutches or other support)

\section{Multivariable logistic regression analysis}

Greater total walking time over the first six post-operative days was predictive of substantial clinical improvement in physical function at six months (ODQ change of $\geq 18.8$ points). For every one hour increase in total

Table 4 Summary of Included and Excluded Data

\begin{tabular}{|c|c|c|}
\hline & Excluded (N) & Included (N) \\
\hline Invited to participate: & & 262 \\
\hline Declined & 17 & \\
\hline \multicolumn{3}{|l|}{ Excluded } \\
\hline Unable to provide informed consent & 4 & \\
\hline Co-existing condition limiting walking & 6 & \\
\hline Withdrew consent & 2 & \\
\hline \multicolumn{2}{|c|}{ Completed pre-operative OM's and activity monitoring: } & $233^{\mathrm{a}}$ \\
\hline Lost/faulty monitor & 27 & \\
\hline Incomplete monitoring period & 16 & \\
\hline Incomplete outcome measures & 19 & \\
\hline Data sets available for multivariable analysis: & & 171 \\
\hline \multicolumn{3}{|l|}{ Included in multivariable analysis ${ }^{\mathrm{b}}$ : } \\
\hline ODQ & 14 & 157 \\
\hline SF-36 (PCS) & 17 & 154 \\
\hline Back pain & $\mathrm{n} / \mathrm{a}$ & $\mathrm{n} / \mathrm{a}$ \\
\hline Leg pain & 18 & $196^{c}$ \\
\hline
\end{tabular}

OM's Outcome measures, ODQ Oswestry Disability Questionnaire, SF-36 (PCS) Short Form 36 Physical Component Summary

${ }^{\text {aT } T o t a l ~ n u m b e r ~ i n c l u d e d ~ i n ~ s e n s i t i v i t y ~ a n a l y s i s ~ u s i n g ~ m u l t i p l e ~ i m p u t a t i o n ~ t o ~}$ estimate missing data; ${ }^{\mathrm{b}}$ Remaining exclusions from individual regression analyses were due to incomplete individual outcome measures or missing independent variable data; ${ }^{C}$ Walking time was not significantly correlated with change in leg pain, the 43 participants with missing activity monitor data included in the multivariable analysis walking time, the odds of achieving the ODQ SCB change threshold increased by $18 \%(\operatorname{Exp}(\beta) 1.18,95 \% \mathrm{CI}$ 1.01-1.37) (Table 6). In addition, a pre-operative pain duration of less than 12 months and lower pre-operative function (higher ODQ score) predicted achievement of the SCB threshold on the ODQ (Table 6).

Total walking time was not predictive of achieving the SCB change threshold on the SF-36 (PCS) or leg pain scores at six months. An age of less than 65 years old, and pre-operative pain of less than 12 months predicted achievement of the SCB threshold (Table 6). There were no significant predictors for achieving the SCB change threshold for back or leg pain.

\section{Sensitivity analysis}

Total walking time remained a significant predictor of functional recovery (change in ODQ score from pre-operative to six months post-operative) using a linear regression model ( $\mathrm{B}=1.54 ; 95 \% \mathrm{CI} 0.60-2.48$ ) (Additional file 1: Table S4 in Appendix). When using multiple imputation models to estimate missing data, total walking time was not a significant predictor of functional recovery or change in pain scores, using either logistic or linear regression analysis (Additional file 1: Table S5, S6 in Appendix).

\section{Discussion}

This study found that greater walking time in the first post-operative week was associated with substantial improvement in self-reported function (ODQ), six months after lumbar surgery. In addition to walking time, experiencing pain for 12 months or less prior to surgery, poor pre-operative physical function and being younger than 65 years were associated with substantial improvement in function on the ODQ and/or the SF-36 (PCS) at six months.

The association between greater post-operative walking time and improved physical function has several implications. Greater walking time early after surgery may be an early indication of a successful surgical intervention, resulting in greater longer-term functional recovery. These patients with a greater walking time may therefore need less formal post-operative rehabilitation. Conversely, patients with a lower post-operative walking time may require more intensive rehabilitation to achieve substantial improvement in physical function. However, while this research suggests that the current focus of physiotherapy intervention on walking may be justified [10-12], further research is required to determine whether providing intervention targeted towards increasing walking time early after surgery then leads to improved longer-term outcome.

There was little overlap in the variables that predicted substantial improvement between the two measures of physical function, which likely reflects the differences in 
Table 5 Outcome measurement: preoperative and six months post-operative; achievement of change thresholds

\begin{tabular}{llllllll}
\hline Outcome & Outcome measure & $\begin{array}{l}\text { Baseline } \\
\text { mean (SD) }\end{array}$ & $\begin{array}{l}\text { Six months } \\
\text { mean (SD) }\end{array}$ & Difference in mean (95\%Cl) & $\begin{array}{l}t \text {-statistic, } p \text {-value } \\
\text { MCID }\end{array}$ & $\begin{array}{l}\text { SCB } \\
N(\%)\end{array}$ \\
\hline Physical function (\%)
\end{tabular}

MCID Minimal Clinically Important Difference, SCB Substantial Clinical Benefit, ODQ Oswestry Disability Questionnaire, SF-36 (PCS) Short Form 36 Physical Component Summary, NRPS Numerical Pain Rating Score

construct between the two measurement tools. Greater walking time was predictive of functional recovery on the ODQ but not the SF-36 (PCS). As the ODQ is designed to directly measure the impact back pain related disability has on physical function [36] it is unsurprising that walking, a form of physical activity, was associated with greater change on the ODQ. In contrast, the physical component summary of the SF-36 is designed to assess physical function in relation to Health Related QOL (HRQOL), and takes into account physical role, bodily pain, general health and mental health, in addition to physical function [37]. This broader definition may explain why alterations to physical activity in isolation did not influence change on the SF-36 (PCS). These results suggest that the ODQ and the SF-36 (PCS) measure distinctly different constructs in this population, a finding consistent with previous research [38].

No patient variables were found to be predictive of substantial improvement in back or leg pain in the multivariable logistic regression model, however on sensitivity analysis restricted pre-operative mobility was predictive of improvement in back-pain scores, and female sex was predictive of improvement in leg pain scores. Sensitivity analysis was conducted using linear regression analysis, where the change in pain from pre to post-operative was assessed as a continuous score rather than dichotomized based on the substantial clinical benefit threshold. This discrepancy may indicate that while restricted pre-operative mobility and female sex are significantly associated with improvement in pain scores, the change in pain over time may not represent a clinically meaningful improvement.

The overall change in outcome after lumbar surgery reported in this study are comparable with previously published results $[7,39]$. While the majority of patients achieved the threshold required to demonstrate substantial improvement in function and pain, around a third did not achieve a minimal clinically important change in outcome. As the substantial clinical benefit threshold was used to dichotomize the data for the logistic regression analysis, we can be confident that these results represent clinically meaningful change, which is of particular importance as the benefit of surgical intervention for lumbar spine pathology remains inconclusive [4-6]. These findings do however emphasize the need for further investigation into interventions designed to optimize longer term recovery of physical function.

\section{Limitations}

There are several limitations to this study that need to be considered when interpreting these results. Up to $34 \%$ of participants who completed the monitoring period were not included in the multivariable analysis, and exclusion of these participants may limit how well the final sample reflects the broader population. However, as there was no statistically significant difference in the pre-operative or demographic variables between the participants that were included in the final analysis and those that were not, we are confident that these findings are representative of a larger sample.

Table 6 Multivariable logistic regression analysis

\begin{tabular}{lllll}
\hline Outcome measure & Variable & $\beta$ & Exp ( 3$)$ & $(95 \% \mathrm{Cl})$ \\
\hline ODQ & Total post-operative walking time (hours) & 0.16 & 1.18 & $(1.02-1.37)$ \\
& Pre-operative pain duration $<12$ months & 1.00 & 2.71 & $(1.28-5.74)$ \\
& Pre-operative function (ODQ categories $\left.^{\mathrm{a}}\right)$ & 1.39 & 4.02 & $(2.33-6.93)$ \\
SF-36 (PCS) & Age $<65$ & 0.86 & 2.36 & $(1.14-4.85)$ \\
& Pre-operative pain duration $<12$ months & 1.26 & 3.52 & $(1.69-7.33)$ \\
\hline
\end{tabular}

Interpretation of results: $\operatorname{Exp}(\beta)$ is equivalent to the odds ratio (OR). The predictor variables may be applied to determine the odds of achieving the SCB threshold for the given outcome measure. For example, for each additional hour of walking the odds of achieving ODQ SCB increases by $18 \%$; for a participant less than 65 years old, the odds of achieving the SF-36 (PCS) SCB is 2.36 greater than those 65 years or over

ODQ, Oswestry Disability Questionnaire; SF-36 (PCS), Short Form 36 Physical Component Summary; ${ }^{a}$ ODQ categories: 1: 0-20, 2: 21-40, 3: 41-59, 4: 60-79, 5: 80100 (reference value: ODQ score 0-20) 
As this research was conducted at a single site, the external validity of this study may be limited. However, patients of 11 different surgeons were included in this study all with differing post-operative protocols, and the presenting characteristics of the patients were consistent with those reported by other spinal surgery studies [7]. Further research across additional settings and patient populations would increase the confidence that these findings are more broadly generalizable.

The aim of this study was to investigate the direct association between patient variables and recovery of physical function after lumbar surgery with routine peri-operative care. Patient care was not standardised or modified in any way from usual care in the hospital setting, and the study was not designed to investigate a specific therapy or exercise intervention. Regression analysis was therefore most suited to examine the direct associations between patient variables and recovery after surgery. It is possible that parameters of the individual peri-operative rehabilitation program, such as the type, intensity, frequency or duration of exercise may have directly influenced outcome at six months, or interacted with the patient variables being examined in this study to indirectly impact outcome. However, our study was not designed to explore more complex predictive models such as an omnibus test of mediation, and as such the parameters of peri-operative rehabilitation were not recorded. Now that a direct association between walking and post-operative outcomes has been established in our study, future research needs to examine the mechanisms driving this relationship by means of more complex models such as mediation analysis.

\section{Conclusion}

This study found that people who spend more time walking in the week after lumbar surgery were more likely to experience substantial improvement in physical function at six months, as measured on the ODQ. Further research is required to ascertain whether intervention designed to increase walking early after lumbar surgery leads to improved recovery of function.

\section{Additional file}

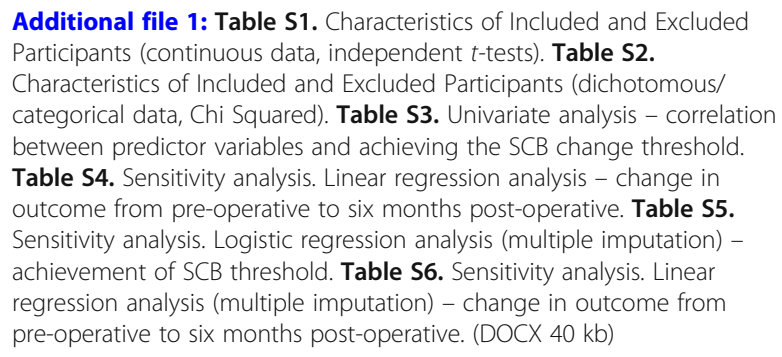

\section{Abbreviations}

BMI: Body Mass Index; EVP: Events per Predictor Variable; GAD-7: Generalized Anxiety Disorder 7-item Scale; HRQOL: Health Related Quality of Life; IPAQ-SF: International Physical Activity Questionnaire Short Form;

MCID: Minimum Clinically Important Difference; NPRS: Numerical Pain Rating Scale; ODQ: Oswestry Disability Questionnaire; OM: Outcome Measure; OR: Odds Ratio; PHQ-9: Patient Health Questionnaire Depression Scale; SCB: Substantial Clinical Benefit; SF-36 (PCS): Short Form 36 Physical Component Summary; SVPHM: St Vincent's Private Hospital Melbourne

\section{Acknowledgements}

Not applicable.

\section{Authors' contributions}

SJG, MD and JAM made a substantial contribution to the study design. All authors (SJG, AH, MD and JAM) made a substantial contribution to the data analysis and interpretation. SJG AH and JM made a substantial contribution towards writing up the manuscript. All authors have read and approved the final manuscript.

\section{Funding}

Funding was received from the Paegasus Neurosurgery Fund (Ref: PNF201502). The funding body had no role in the design of the study, collection, analysis, or interpretation of the data, or writing of the manuscript

\section{Availability of data and materials}

The datasets used and/or analysed during the current study are available from the corresponding author on reasonable request.

\section{Ethics approval and consent to participate}

Ethics approval was obtained from the St Vincent's Hospital Melbourne Human Research Ethics Committee (Reference: LRR 098/15). Written, informed consent was obtained from all individual participants included in the study.

This study was retrospectively registered with the Australian New Zealand Clinical Trials Registry (ANZCTR) on the 7th June 2016, registration number 12616000747426.

\section{Consent for publication}

Not applicable.

\section{Competing interests}

The Authors have no conflicts of interest to declare.

Received: 14 April 2019 Accepted: 30 August 2019

Published online: 11 September 2019

\section{References}

1. Bae HW, Rajaee SS, Kanim LE. Nationwide trends in the surgical management of lumbar spinal stenosis. Spine. 2013;38(11):916-26.

2. Harris IA, Dao AT. Trends of spinal fusion surgery in Australia: 1997 to 2006. ANZ J Surg. 2009;79(11):783-8.

3. Kobayashi K, Ando K, Nishida Y, et al. Epidemiological trends in spine surgery over 10 years in a multicenter database. Eur Spine J. 2018;27(8): 1698-703.

4. Jacobs WC, van Tulder M, Arts $M$, et al. Surgery versus conservative management of sciatica due to a lumbar herniated disc: a systematic review. Eur Spine J. 2011;20(4):513-22.

5. Phillips FM, Slosar PJ, Youssef JA, et al. Lumbar spine fusion for chronic low back pain due to degenerative disc disease: a systematic review. Spine. 2013;38(7):E409-22.

6. Zaina F, Tomkins-Lane C, Carragee E, Negrini S. Surgical versus nonsurgical treatment for lumbar spinal stenosis. Cochrane Database of Syst Rev. 2016;1:Cd010264.

7. Weinstein JN, Tosteson TD, Lurie JD, Tosteson A, Blood E, Herkowitz H, Cammisa F, Albert T, Boden SD, Hilibrand A, Goldberg H, Berven S, An $\mathrm{H}$. Surgical versus non-operative treatment for lumbar spinal stenosis four year results of the spine patient outcomes research trial (SPORT). Spine. 2010;35:1329-38. 
8. Gilmore SJ, McClelland JA, Davidson M. Physiotherapeutic interventions before and after surgery for degenerative lumbar conditions: a systematic review. Physiother. 2015;101(2):111-8. https://doi.org/10.1016/j.physio.2014.06.007.

9. Oosterhuis T, Costa LOP, Maher CG, de Vet HCW, van Tulder MW, Ostelo RWJG. Rehabilitation after lumbar disc surgery. Cochrane Database Syst Rev. 2014;3. https://doi.org/10.1002/14651858.CD003007.pub3.

10. Gilmore SJ, McClelland JA, Davidson M. Physiotherapy management of patients undergoing lumbar spinal surgery for degenerative conditions: a survey of Australian physiotherapists. N Z J Physiother. 2016;44(2):105-12.

11. Rushton A, Heneghan N, Heap A, et al. Survey of current physiotherapy practice for patients undergoing lumbar spinal fusion in the UK. Spine. 2014;39(23):E1380-7.

12. Williamson $E$, White $L$, Rushton A. A survey of post-operative management for patients following first time lumbar discectomy. Eur Spine J. 2007;16(6):795-802.

13. Mancuso CA, Duculan R, Graig CM, Girardi FP. Psychosocial variables contribute to length of stay and discharge destination after lumbar surgery independent of demographic and clinical variables. Spine J. 2018;43(4):281-6.

14. Hey HWD, Luo N, Chin SY, Lau ETC, Wang P, Kumar N, Lau L, Ruiz JN, Thanbiah JS, Lui KG, Wong $H$. The predictivive value of preoperative health-related quality-of-life scores on postoperative patient-reported outcome scores in lumbar spine surgery. Global Spine J. 2018;8(2):156-63.

15. Kanaan SF, Arnold PM, Burton DC, Yeh H, Loyd L, Sharma NK. Investigating and predicting early lumbar spine surgery outcomes. J Allied Health. 2015;44(2):83-90.

16. Pearson A, Lurie J, Tosteson T, Zhao W, Abdu W, Weinstein J. Who should have surgery for spinal stenosis?: treatment effect predictors in SPORT. Spine. 2012;37:1791-802

17. Appaduray SP, Lo P. Effects of diabetes and smoking on lumbar spinal surgery outcomes. J Clin Neurosci. 2013;20:1713-7.

18. Archer KR, Seebach CL, Mathis SL, Riley lii LH, Wegener ST. Early postoperative fear of movement predicts pain, disability, and physical health six months after spinal surgery for degenerative conditions. Spine J. 2014;14(5):759-67.

19. Gilmore SJ, Davidson M, Hahne AJ, McClelland JA. The validity of using activity monitors to detect step count after lumbar fusion surgery. Disabil Rehabil. 2018. https://doi.org/10.1080/09638288.2018.1509140.

20. Gilmore SJ, Hahne AJ, Davidson M, McClelland JA. Physical activity pattersons after lumbar spinal surgery. Disabil Rehabil. 2019;15:1-7.

21. Mancuso CA, Duculan R, Girardi FP. Healthy physical activity levels below recommended thresholds two years after lumbar spine surgery. Spine. 2017; 42(4):E241-E7. https://doi.org/10.1097/BRS.0000000000001757.

22. Smuch M, Muaremi A, Zheng P, Norden J, Sinha A, Hu R, Tomkins-Lane C. Objective measurement of function following lumbar spinal stenosis decompression reveals improved functional capacity with stagnant real-life physical activity. Spine J. 2018;18(1):15-21.

23. Gilmore S, McClelland JA, Davidson M. Does walking after lumbar spinal surgery predict recovery of function at six months? Protocol for a prospective cohort study. BMC Musculoskelet Disord. 2016;17:472.

24. Kroenke K, Spitzer RL, Williams JBW. The PHQ-9. J Gen Intern Med. 2001;16:606-13.

25. Choi Y, Mayer TG, Williams MJ, Gatchel RJ. What is the best screening test for depression in chronic spinal pain patients? Spine J. 2014;14:1175-82.

26. Spitzer RL, Kroenke K, Williams JB, Lowe B. A brief measure for assessing generalized anxiety disorder: the GAD-7. Arch Intern Med. 2006;166:1092-7.

27. Craig CL, Marshall AL, Sjostrom M, Bauman AE, Booth ML, Ainsworth BE, Pratt M, Ekelund U, Yngve A, Sallis JF, Oja, P. International physical activity questionnaire: 12country reliability and validity. Med Sci Sports Exerc 2003;35:1381-1395.

28. Helmerhorst HJ, Brage S, Warren J, Besson H, Ekelund U. A systematic review of reliability and objective criterion-related validity of physical activity questionnaires. Int J Behav Nutr Phys Act. 2012;9:103.

29. Davidson M, Keating JL. A comparison of five low back disability questionnaires: reliability and responsiveness. Phys Ther. 2002;82(1):8-24

30. Ware JEJP, Sherbourne CDP. The MOS 36-Item short-form health survey (SF-36): I. conceptual framework and item selection. Med Care. 1992;30(6):473-83.

31. Chapman JR, Norvell DC, Hermsmeyer JT, et al. Evaluating common outcomes for measuring treatment success for chronic low Back pain. Spine. 2011;36:S54-68.

32. Ostelo RW, Deyo RAP, Stratford PP, et al. Interpreting change scores for pain and functional status in low Back pain: towards international consensus regarding minimal important change. Spine. 2008;33(1):90-4.
33. Glassman SD, Copay AG, Berven SH, et al. Defining Substantial Clinical Benefit Following Lumbar Spine Arthrodesis. J Bone Joint Surg Am. 2008; 90(9):1839-47.

34. Park J, Kim D, Seo D, et al. Predictors of response to a medical branch block: MRI analysis of the lumbar spine. J Clin Med. 2019;8(4):538-49.

35. Vittinghoff $E, M c C u l l o c h ~ C E$. Relaxing the rule of ten events per variable in logistic and cox regression. Am J Epidemiol. 2007;165(6):710-8.

36. Fairbank J, Couper J, Davies JB, O'Brien JP. The Oswestry low Back pain questionnaire. Physiother. 1980;66(8):271-3.

37. Ware J, Kosinski M. SF-36v2 health survey: administration guide for clinical trial investigators. Lincoln: QualityMetric Incorporated; 2008.

38. Bombardier C. Outcome assessments in the evaluation of treatment of spinal disorders: summary and general recommendations. Spine. 2000; 25(24):3100-3.

39. Fritsch CG, Ferreira ML, Maher CG, et al. The clinical course of pain and disability following surgery for spinal stenosis: a systematic review and meta-analysis of cohort studies. Eur Spine J. 2017;26(2):324-35.

\section{Publisher's Note}

Springer Nature remains neutral with regard to jurisdictional claims in published maps and institutional affiliations.

Ready to submit your research? Choose BMC and benefit from:

- fast, convenient online submission

- thorough peer review by experienced researchers in your field

- rapid publication on acceptance

- support for research data, including large and complex data types

- gold Open Access which fosters wider collaboration and increased citations

- maximum visibility for your research: over $100 \mathrm{M}$ website views per year

At $\mathrm{BMC}$, research is always in progress.

Learn more biomedcentral.com/submissions 